\section{Development and Evaluation of Diploid and Polyploid Hibiscus moscheutos}

Zhitong Li and John M. Ruter ${ }^{1}$

Institute of Plant Breeding, Genetics and Genomics, University of Georgia, 111 Riverbend Road, Athens, GA 30602; and Department of Horticulture, University of Georgia, 1111 Miller Plant Sciences Building, Athens, GA 30602

Additional index words. chromosome doubling, colchicine, flow cytometry, oryzalin, phytophthora, ploidy manipulation, seedling soaking, sterility Abstract. Hibiscus moscheutos L. is an herbaceous hibiscus native to eastern North
America that has been a popular landscape and container plant exhibiting large and
colorful flowers in the summer. However, unsightly fruit develop and remain on the
stalks at the end of the blooming season, which greatly decreases the ornamental value.
Thus, breeding for sterility was attempted through ploidy level manipulation to reduce
formation and growth of seed stalks, and to improve blooming vigor and longevity.
Colchicine and oryzalin were used as mitotic inhibitors to induce tetraploid breeding
lines that could be used to develop sterile triploids. Germinated seedlings of 'Luna Red'
were soaked in three concentrations of each doubling agent for three different durations.
Exposure to a low concentration of colchicine solution for a long time or to a low
concentration of oryzalin for a short period was found to be effective in yielding a high
number of tetraploids with a low rate of mortality. Triploids were obtained from the
traditional method of crossing tetraploids with diploids. Triploid and tetraploid plants
showed a decrease in height with a more compact form. Leaves of tetraploid plants were
more ruffled, with an increase in overall leaf thickness, but were not different from leaves
of diploids and triploids in regard to leaf mass per area (LMA). Triploid plants bloomed
longer but had smaller flowers than diploid plants. Although the whole planting was
infected by aerial phytophthora, diploid, tetraploid, and triploid plants were significantly
different in their tolerances: all diploid branches were infected, but only a minor
infection occurred on one triploid branch, and the transmission remained slow. Flowers
of tetraploid plants failed to produce pollen, whereas flowers of triploid plants produced
only nonviable pollen grains and fruits aborted after pollination, which led to infertility
of induced triploids.

Hibiscus moscheutos L., often called swamp rose-mallow or hardy hibiscus, is a perennial plant native to the wetland areas in the eastern region of North America (USDA zone $5 \mathrm{a}-10 \mathrm{~b}$ ) (Flora of North America Editorial Committee, 1993+; Winters, 1970). As a landscape ornamental, it has long been bred for compact stature, larger flowers in various colors, unique leaf colors, and shapes. In the mid-Atlantic region, flowers are produced daily from July to September (Spira, 1989); however, unsightly fruit eventually develop and remain on the stalks until the end of the season. This unsightliness greatly decreases the ornamental value. Thus, breeding for sterility is attempted to avoid formation and growth of seed stalks, and to improve blooming vigor and longevity.

Induction of polyploid genotypes is an effective means of producing enhanced characteristics and increased sterility. In breeding

\footnotetext{
Received for publication 14 Dec. 2016. Accepted for publication 20 Mar. 2017.

We acknowledge Ball ${ }^{\circledR}$ Horticultural Company for providing the seeds used in this work and Vickie Waters for technical assistance.

This manuscript is from a thesis submitted by Zhitong Li in partial fulfillment of the requirements for the MS degree.

${ }^{1}$ Corresponding author. E-mail: ruter@uga.edu.
}

polyploidization, immersion of seeds in doubling agents was the first to exhibit satisfactory performance (Blakeslee and Avery, 1937; Lehrer et al., 2007; Rubuluza et al., 2007). Inducing polyploids by submerging germinated seedlings has been reported on lilac (Fiala, 1988) and hypericum (Olsen et al., 2006), but not in the genus Hibiscus.

In this study, we sought to determine a protocol using H. moscheutos 'Luna Red' to induce tetraploids and to further raise sterile triploid clones. A gamete containing two sets of chromosomes provided by tetraploid parents combines with a gamete containing one set of chromosomes provided by diploid pollen and forms a triploid zygote (Acquaah, 2007). After identification of ploidy levels from induction treatments, diploid, triploid, and tetraploid plants were evaluated regarding various morphological traits.

\section{Materials and Methods}

Plant materials. A popular inbred H. moscheutos cultivar on the market, one with large flower petals and dwarf compact stature, is 'Luna Red' (Leue, 2005). Seeds (provided by Ball ${ }^{\circledR}$ Horticultural Company) were allowed to germinate and then were treated. To facilitate harvesting whole seedlings for soaking treatment, seeds were sown in pure sand and covered by a $0.5-\mathrm{cm}$ layer of vermiculite under mist with $5 \mathrm{~s}$ of misting every $8 \mathrm{~min}$. Seedlings were ready to be treated once they reached the "cotyledon stage" (Contreras et al., 2009) where cotyledons are fully expanded and shoot meristems are forming.

Treatment methods. Hibiscus moscheutos 'Luna Red' seedlings in the "cotyledon stage" were removed from the sand and treated with chemicals. Seedling-soaking experiments were carried out as two studies using colchicine and oryzalin. Each study was designed as a two-way factorial linear model with three levels of chemical concentration and three levels of exposure duration; after adding a control group, there were 10 experimental units for each study. Seedlings were exposed to $0.025 \%, 0.05 \%$, and $0.1 \%$ $(\mathrm{w} / \mathrm{v})$ colchicine $[\geq 95 \%$ (HPLC) powder; Sigma-Aldrich ${ }^{\circledR}$, St. Louis, MO] solution for 6,12 , and $24 \mathrm{~h}$ and in 100,125 , and $150 \mu \mathrm{M}$ oryzalin (Surflan $^{\circledR}$ A.S.; Southern Agricultural Insecticides, Inc., Hendersonville, NC) solution for 6,12 , and $24 \mathrm{~h}$, respectively, under conditions of dim fluorescent light and a room temperature of $25{ }^{\circ} \mathrm{C}$. Within each experimental unit, there were eight replicates and five seedlings per replicate. During the treatment, all seedlings were placed in amber, wide-neck reagent bottles on a rotational shaker (No. 3590; Laboratory-Line ${ }^{\circledR}$ Instruments Inc., Tripunithura, Kochi, India) at a speed of 120 $\mathrm{rpm}$. All treated seedlings were cleaned under running tap water for $1 \mathrm{~h}$ to remove any residue. Seedlings were then wrapped in damp task wipers (Kimwipes; Kimberly-Clark Professional, Roswell, GA) in petri dishes (VWR ${ }^{\circledR}$ 
international, Radnor, PA) to be transferred to

Greenhouse production. Seedlings were planted in potting media (Jolly Gardener ${ }^{\circledR}$ Proline C/B Growing Mix; Jolly Gardener Products Inc., Poland, ME) supplemented with $600 \mathrm{~g} \cdot \mathrm{m}^{-3}$ Micromax micronutrients (Everris ${ }^{\circledR}$, Geldermalsen, the Netherlands) and $4 \mathrm{~kg} \cdot \mathrm{m}^{-3} 15 \mathrm{~N}-4.0 \mathrm{P}-10 \mathrm{~K}$ slow-release fertilizer (Osmocote ${ }^{\circledR}$ Plus, Marysville, $\mathrm{OH}$ ) in $10-\mathrm{cm}$ containers. Five seedlings were planted in each container. Containers were placed in flats in a randomized complete block design with 10 blocks. The flats were placed in a shaded area for 6 weeks, and then in a partially shaded area for 4 weeks until being moved to full sun light conditions. The greenhouse temperature was set to $25{ }^{\circ} \mathrm{C}$ during the daytime and $20{ }^{\circ} \mathrm{C}$ during the night with natural lighting. Plants were fertilized with $200 \mathrm{mg} \cdot \mathrm{L}^{-1} \quad 20 \mathrm{~N}-4.4 \mathrm{P}-16.6 \mathrm{~K}$ water-soluble fertilizer (Jack's Professional ${ }^{\circledR}$; JR Peters Inc, Allentown, PA) weekly.

Survival data were taken on the seedlings at 8 weeks after treatment. As the seedlings expanded in size, they were transplanted into potting media with Micromax ${ }^{\circledR}$ mix in $2.8-\mathrm{L}$ containers. A ploidy level test was performed after treated plants were developed with regular, continuous growth, but before initiation of flower buds.

Ploidy level analysis. The ploidy levels of treated plants were determined by measuring the fluorescence intensity of stained nuclei relative to the ploidy of a known control plant ducted on a CyFlow ${ }^{\circledR}$ Ploidy Analyser flow cytometer (Partec GmbH, Münster, Germany). At most, $1-\mathrm{cm}^{2}$ leaf tissue of the second spreading leaf from each plant was sampled and then chopped with a sharp stainless razor blade (Electron Microscopy Sciences, PA) into $\approx 1-2 \mathrm{~mm}^{2}$ particles in nuclei extraction buffer (CyStain ${ }^{\circledR}$ ultraviolet Precise P; Sysmex Partec, Görlitz, Germany) and allowed to rest for $30 \mathrm{~s}$ in the solution. The sample particles were removed through straining in a $40-\mu \mathrm{m}$ mesh filter, and a nuclei staining buffer (CyStain ${ }^{\circledR}$ ultraviolet Precise P; Sysmex Partec, Görlitz, Germany) was added into the remaining solution with intact DNA for at least $2 \mathrm{~min}$.

When the solution was taken up through the flow cytometer, histograms were automatically generated. Before scanning any samples of treated plants, the reference fluorescence of stained nuclei was set by scanbasis on which diploid, triploid, tetraploid, or

Tetraploid $\times$ diploid crosses. Hibiscus moscheutos flowers bloom for only $1 \mathrm{~d}$ (Spira, 1989), and fresh pollen is produced between 8:00 and 10:00 AM in the morning on a sunny day (Shimamura et al., 2005). Hand pollination was conducted in the greenhouse during the blooming season of H. moscheutos. Flowers of diploid 'Luna Red' plants with abundant pollen were collected daily to cross with flowers of identified tetraploids between 8:00 and 10:00 AM in the morning. the greenhouse. via flow cytometry. The analysis was conning a known diploid sample, and this was the mixaploid samples were identified.
Pollen was gently rubbed on the stigma of tetraploids until fully covering the stigma. A pollination tag was placed around the flower pedicel with information of accession number, maternal and fraternal parents, and pollination date. Over 1300 crosses were made, and data were recorded with regard to whether seeds aborted or matured.

Seeds from tetraploid $\times$ diploid crosses were harvested and cleaned from mature capsules. The seed number of each specific cross was counted, and all seeds were germinated in potting media supplemented with micronutrients and Osmocote ${ }^{\circledR}$ fertilizer $(15 \mathrm{~N}-4.0 \mathrm{P}-10 \mathrm{~K}$ slow-release fertilizer) in $18-\mathrm{cm}$ containers. Seeds germinated gradually, and seedlings with more than three true leaves were tested for ploidy level via flow cytometry methods described above. Identividually into $7.5-\mathrm{cm}$ containers for further evaluation.

Three-node stem cuttings were taken from tetraploids before they entered dormancy. After being dipped in $300 \mathrm{mg} \cdot \mathrm{L}^{-1}$ K-IBA (indole-3-butyric acid potassium salt; Sigma-Aldrich $^{\circledR}$, St. Louis, MO) solution for $3 \mathrm{~s}$ at the base, cuttings were planted in potting media in $10-\mathrm{cm}$ containers with $25^{\circ} \mathrm{C}$ bottom heat under a shaded mist bench for further root development. When roots were well established, cuttings were removed from mist and transferred to regular greenhouse conditions for winter. Diploid 'Luna Red' and putative triploid seeds were germinated in flats, and germination percentages were recorded. After ploidy level determination of triploid plants, diploid and triploid seedlings were transferred to $10-\mathrm{cm}$ containers and kept in the greenhouse until the growing season.

Characteristic measurement. Wellestablished diploid, triploid, and tetraploid plants were trimmed back to a height of $15 \mathrm{~cm}$. Before planting, preemergent herbicides Surflan ${ }^{\circledR}\left(40.4 \%\right.$ oryzalin, Surflan ${ }^{\circledR}$ A.S.; Southern Agricultural Insecticides Inc., Hendersonville, NC) and Gallery ${ }^{\circledR}$ (Isoxaben; Dow $^{\circledR}$ AgroSciences, Indianapolis, IN) were sprayed in the field at a rate of $0.4 \mathrm{~L} \cdot \mathrm{ha}^{-1}$ and $2.0 \mathrm{~kg} \cdot \mathrm{ha}^{-1}$, respectively, and field soil was amended with $15 \mathrm{~N}-0 \mathrm{P}-12.5 \mathrm{~K}$ fertilizer at

Table 1. Summary of results for soaking germinated seedlings of Hibiscus moscheutos 'Luna Red' in colchicine solutions. The sample size was $n=40$ seedlings per treatment.

\begin{tabular}{|c|c|c|c|}
\hline Colchicine concn (w/v) & Exposure duration (h) & Survival rate $(\%)^{z}$ & Tetraploid conversion rate $(\%)$ \\
\hline $0.025 \%$ & 6 & 97.5 & 12.5 \\
\hline $0.025 \%$ & 12 & 92.5 & 22.5 \\
\hline $0.025 \%$ & 24 & 72.5 & 17.5 \\
\hline $0.05 \%$ & 6 & 87.5 & 10.0 \\
\hline $0.05 \%$ & 12 & 62.5 & 17.5 \\
\hline $0.05 \%$ & 24 & 52.5 & 17.5 \\
\hline $0.1 \%$ & 6 & 50.0 & 12.5 \\
\hline $0.1 \%$ & 12 & 37.5 & 10.0 \\
\hline $0.1 \%$ & 24 & 40.0 & 20.0 \\
\hline \multicolumn{4}{|l|}{ Analysis of variance ${ }^{y}$} \\
\hline \multicolumn{2}{|l|}{ Concentration } & $* * *$ & NS \\
\hline \multicolumn{2}{|l|}{ Exposure duration } & $* * *$ & NS \\
\hline \multicolumn{2}{|c|}{ Concentration $\times$ exposure duration } & * & NS \\
\hline
\end{tabular}

${ }^{\mathrm{z}}$ Survival rate was assessed 8 weeks after initial treatment.

${ }^{\mathrm{y}} \mathrm{NS}=$ not significant, $*$ significant at $P \leq 0.05, * * *$ significant at $P \leq 0.001$.

a rate of $9.3 \mathrm{~kg} \cdot \mathrm{ha}^{-1}$ (Tri County Fertilizer and Specialty, Honea Path, SC) and Epsom ${ }^{\circledR}$ salts (magnesium sulfate; Saltworks ${ }^{\circledR}$, Woodinville, WA) at a rate of $96.0 \mathrm{~kg} \cdot \mathrm{ha}^{-1}$. Plants were placed $1.8 \mathrm{~m}$ apart between rows and $1.2 \mathrm{~m}$ apart within rows. The field was maintained using 16-23 ml. $\mathrm{L}^{-1}$ Honcho $^{\circledR}$ (Glyphosate; Monsanto Agrochemical Company, Greater St. Louis, MO) for weed control. Drip irrigation was implemented for 1-2 h every week, but the frequency was adjusted as needed.

Under open field conditions, morphological data were taken on all plants of different ploidy levels. After the plants reached full bloom, plant heights were measured. Leaf characteristics were measured on fully expanded leaves, recording leaf area using a Li-3100C leaf area meter (LI-COR ${ }^{\circledR}$ Biosciences, Lincoln, NE), leaf thickness using a micrometer (6" Digital Caliper; Pittsburgh $^{\circledR}$, Camarillo, CA), leaf greenness using a chlorophyll meter (Minolta SPAD-502; Spectrum ${ }^{\circledR}$ Technologies, Inc., Aurora, IL), and LMA. Leaf mass per area $\left(\mathrm{mg} \cdot \mathrm{cm}^{-2}\right)$ is the ratio of leaf dry mass to its area size, which can be used to assess leaf density and resistance to herbivory (De la Riva et al., 2016; Lambers et al., 1998). LMA was measured by sampling 20 leaf punches $(0.85 \mathrm{~cm}$ in diameter) taken from each plant with a hole puncher. Leaf tissue was ovendried at $104{ }^{\circ} \mathrm{C}$ for $17 \mathrm{~h}$ before measuring the dry weight of each sample. Floral characteristics measured were blooming period (start, peak, and end), flower diameter, petal redness using an anthocyanin content meter (ACM200plus; Opti-Sciences, Hudson, NH), and pollen presence and viability. Pollen viability was tested by observing pollen stainability. This was done by staining pollen with $1 \%$ acetocarmine solution at $25^{\circ} \mathrm{C}$ for $3 \mathrm{~h}$. Pollen viability was also identified by observing pollen tube elongation in Brewbaker and Kwack (BK) agar pollen germination media (Brewbaker and Kwack, 1963) after $24 \mathrm{~h}$ of culture at $25{ }^{\circ} \mathrm{C}$ in a growth incubator (Thermo Fisher ${ }^{\circledR}$ Scientific, Precision, Waltham, MA). Tolerance to aerial phytophthora (Phytophthora spp.) was visually rated in each ploidy level group and compared between groups. On a scale of zero to three, fied triploids were then transplanted indi- 
" 0 " = no phytophthora infection, " 1 " = light phytophthora infection with less than $30 \%$ branches infected, " 2 " = medium phytophthora infection with between $30 \%$ and $60 \%$ branches infected, and " 3 " = severe phytophthora infection with over $60 \%$ branches infected.

Data analysis. Estimation of survival rate and tetraploid transformation rate were made using binomial regression, and morphological traits comparisons were conducted using one-way analysis of variance (ANOVA) and Tukey's test among ploidy levels. All statistical analyses were performed on $\mathrm{R}$ computing software ( $\mathrm{R}$ Development Core Team, 2015).

\section{Results}

Analysis of tetraploid induction. After being treated in colchicine or oryzalin solutions, seedlings were transplanted in potting soil, but remained stunted for several weeks. During the last stage of stagnation, colchicine-soaked seedlings started showing signs of swollen and splitting bases, and lesions formed. On the seedlings which survived, the plants soon resumed growth and developed leaves and stems more quickly than seedlings in the control group; seedlings that did not survive died with one or multiple visible lesions at the stem base. Hibiscus seedlings that survived the "chemical shock" developed regular stems and leaves, but seedlings that died during or slightly after the stagnation stage underwent root growth inhibition and died from root destruction.

Both colchicine and oryzalin effectively induced tetraploids from soaking germinated seedlings of $H$. moscheutos; survival rate and tetraploid conversion percentage, however, varied greatly depending on the concentration and exposure duration under each chemical study. In the colchicine-soaking study, a binomial linear regression was fitted $\left(R^{2}=\right.$ 0.487 ) for seedling survival percentages with two significant main effects: colchicine concentration $(P=0.001)$ and exposure duration $(P<0.001)$. A significant interaction effect $(P=0.01)$ appeared between two main variables (Table 1; Fig. 1A). The highest percentage $(97.5 \%)$ of seedlings survived at the lowest concentration $(0.025 \%)$ and the shortest exposure duration $(6 \mathrm{~h})$; the survival percentage dropped to $40.0 \%$ at the highest colchicine concentration $(0.1 \%)$ when treated for the longest time $(24 \mathrm{~h})$ (Table 1). The survival of seedlings decreased as colchicine increased in concentration and also as exposure duration increased, although in different magnitudes. Survival percentage decreased at a similar pace at colchicine concentration of $0.025 \%$ and $0.05 \%$; meanwhile, when the concentration went up to $0.1 \%$, there was a sudden decrease in survival percentages (Fig. 1A). With regard to exposure duration, survival percentage decreased as the duration of exposure went up; however, the decrease was accelerated when exposure duration was greater than $12 \mathrm{~h}$, particularly when exposure duration was associated with lower
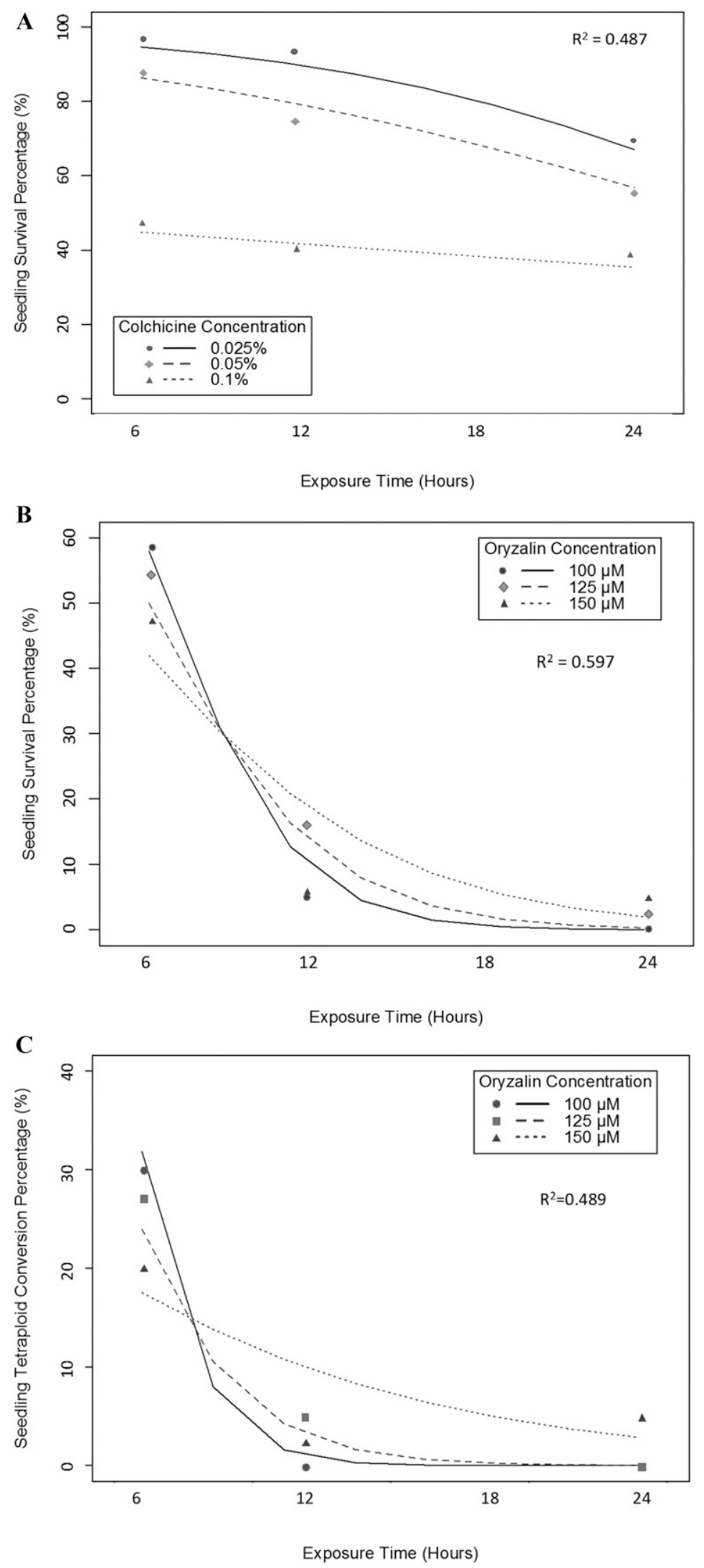

Fig. 1. (A) Survival percentage of Hibiscus moscheutos 'Luna Red' seedlings after soaking in three levels of colchicine concentration and three levels of exposure time. There were significant main effects on both colchicine concentration and exposure time, as well as an interaction effect between them $\left(R^{2}=\right.$ 0.487). (B) Survival percentage of Hibiscus moscheutos 'Luna Red' seedlings after treatments of three oryzalin concentrations and three different exposure times. A binomial regression was conducted with an overall fit of $R^{2}=0.597$. (C) Tetraploid conversion percentage of Hibiscus moscheutos 'Luna Red' seedlings after being soaked in combinations of three oryzalin concentrations and three exposure times. A binomial regression was conducted with an overall fit of $R^{2}=0.489$. 
concentrations $(0.025 \%$ and $0.05 \%)$. Decrease in survival rate was similar according to exposure duration at the concentration of $0.1 \%$.

Examination of the ploidy level of each surviving seedling by flow cytometry indicated that the highest conversion percentage was $20.0 \%$, induced under $0.1 \%$ colchicine for $24 \mathrm{~h}$, and the lowest conversion percentage was $10.0 \%$, induced under $0.1 \%$ colchicine solution for $6 \mathrm{~h}$ (Table 1). Tetraploid conversion percentage was not significantly affected by colchicine concentration, exposure duration, or their interaction in this two-factor linear model.

Oryzalin-treated seedlings displayed lower survival rates overall in contrast to colchicinetreated seedlings. The highest survival percentage was $57.5 \%$, and the lowest survival rate was $0 \%$ (Table 2). Results of a binomial regression analysis revealed that there was statistical significance for oryzalin concentration $(P=0.03)$, exposure duration $(P=$ $0.002)$, and their interaction effect $(P=0.03)$ (Table 3; Fig. 1B). Seedling survival percentage decreased as oryzalin concentration increased or as the exposure duration increased. At $6 \mathrm{~h}$ of chemical exposure, the lowest oryzalin concentration $(100 \mu \mathrm{M})$ yielded the highest survival rate, but there is a more severe drop with exposure duration for the lowest oryzalin concentration than for the other concentrations (Fig. 1B). Between 6 and $12 \mathrm{~h}$ of chemical exposure, the variable interaction entered into play, and a higher percentage of seedlings survived under treatments of $150 \mu \mathrm{M}$ oryzalin solutions. Survival percentages of plants treated with 100 and $125 \mu \mathrm{M}$ oryzalin decreased drastically between 6 and $12 \mathrm{~h}$ of exposure, and continued to decrease as the exposure duration reached $20 \mathrm{~h}$ (Fig. 1B). The rate of decrease in survival percentage was less severe for the $150 \mu \mathrm{M}$ oryzalin treatments than it was in the other treatments.

Some of the low efficiencies of oryzalin treatments for conversion of tetraploids were due to low survival percentage (Table 2). Oryzalin concentration $(P=0.008)$ and exposure duration $(P=0.007)$ were both significant as main effects, as was their interaction $(P=0.01)$. Percentages of tetraploid conversion decreased steadily as the exposure duration increased under $150 \mu \mathrm{M}$ oryzalin concentration, whereas there was a more sharply decreasing curve for concentrations of 100 or $125 \mu \mathrm{M}$ (Fig. 1C). At $6 \mathrm{~h}$ of exposure duration, the lower concentration contributed to a higher tetraploid conversion, possibly due to a larger number of surviving seedlings (Table 2; Fig. 1C). Above $6 \mathrm{~h}$ of exposure duration, the prediction line appeared to show an optimal efficiency in induction of tetraploidy at an oryzalin concentration of $150 \mu \mathrm{M}$ (Fig. 1C).

Tetraploid $\times$ diploid crosses. Though only a few crosses were viable and eventually produced seeds, tetraploids were receptive to diploid pollen. Crosses were made between flowers of identified tetraploid plants and diploid flowers of 'Luna Red'. Hundreds of crosses were attempted, but only 15 crosses yielded viable seeds.

After seeds germinated, the ploidy level of every seedling was confirmed via flow

Table 2. Summary of results for soaking germinated seedlings of Hibiscus moscheutos 'Luna Red' in oryzalin solutions. The sample size was $n=40$ seedlings per treatment.

\begin{tabular}{lccc}
\hline Concn $(\mu \mathrm{M})$ & Exposure duration $(\mathrm{h})$ & Survival rate $(\%)^{\mathrm{z}}$ & Tetraploid conversion rate $(\%)$ \\
\hline 100 & 6 & 57.5 & 30.0 \\
100 & 12 & 5.0 & 0 \\
100 & 24 & 0 & 0 \\
125 & 6 & 55.0 & 27.5 \\
125 & 12 & 15.0 & 5.0 \\
125 & 24 & 2.5 & 0 \\
150 & 6 & 47.5 & 20.0 \\
150 & 12 & 5.0 & 2.5 \\
150 & 24 & 5.0 & 5.0 \\
Analysis of variance & & & $*$ \\
Concentration & & $* *$ & $*$ \\
Exposure duration & $*$ & $*$ \\
Concentration $\times$ exposure duration & $*$ & $*$
\end{tabular}

${ }^{\mathrm{z}}$ Survival rate was assessed 6 weeks after initial treatment.

y*significant at $P \leq 0.05, * *$ significant at $P \leq 0.01$.

cytometry, with 27 seedlings being triploid All confirmed triploid seedlings were from crosses of oryzalin-induced plants. They were from one of the four chemical soaking treatments: $100 \mu \mathrm{M}$ oryzalin treating for $6 \mathrm{~h}$, $125 \mu \mathrm{M}$ oryzalin treating for $12 \mathrm{~h}, 150 \mu \mathrm{M}$ oryzalin treating for $6 \mathrm{~h}$, or $150 \mu \mathrm{M}$ oryzalin treating for $24 \mathrm{~h}$. Throughout the whole experiment, an inbred diploid cultivar was adopted and induced into autotetraploids, i.e., plant material that contains four sets of similar gametes (Acquaah, 2007). Autotetraploidy was developed only for short-term enhancements and thus could be adopted toward breeding purposes (Ranney, 2006), but this state was difficult to maintain and usually got lost in the flow of plant evolution because of its instability (Levin, 1983; Soltis et al., 2014). Therefore, such a situation could be a result of harvesting supposed triploid seeds from a flower produced on a diploid branch, a branch which had earlier reverted from a confirmed tetraploid plant. This possible reversion acted against the harvest gain of triploid seeds; however, more seeds coming from an oryzalininduction background were maintained as triploids as opposed to those of a colchicineinduction background.

Characteristic measurement and comparison. Morphological measurements were recorded after diploid, triploid, and tetraploid plants were well established in the field. Instead of being "enlarged," tetraploid and triploid plants appeared to be further dwarfed after being induced from their compact, diploid homologs (Table 3). Leaves of tetraploid plants displayed a highly ruffled leaf texture because of an increase in thickness over leaves of diploids, but there was no difference in LMA. Tetraploids had a shorter stature than diploids, with darker green and more ruffled leaves (Fig. 2);

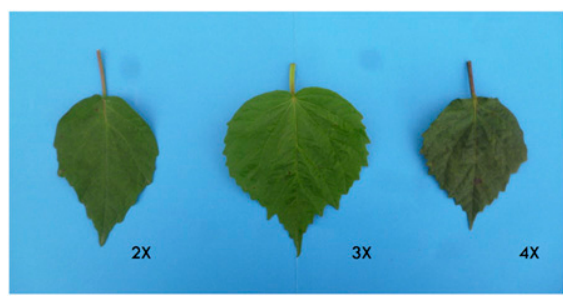

Fig. 2. Diploid, triploid, and induced tetraploid leaves of Hibiscus moscheutos 'Luna Red'.

Table 3. Morphological characteristics were measured on diploid, triploid, and tetraploid Hibiscus moscheutos 'Luna Red' in the field. Tukey's honestly significant difference test was performed, and comparisons were made between triploid and diploid, and between tetraploid and diploid plants.

\begin{tabular}{|c|c|c|c|c|c|c|c|c|c|c|}
\hline Ploidy level & $\begin{array}{c}\text { Plant } \\
\text { ht }(\mathrm{cm})\end{array}$ & $\begin{array}{l}\text { Leaf area } \\
\left(\mathrm{cm}^{2}\right)\end{array}$ & $\begin{array}{c}\text { Leaf } \\
\text { greenness } \\
\text { index }\end{array}$ & $\begin{array}{c}\text { Leaf } \\
\text { thickness }(\mathrm{mm})\end{array}$ & $\begin{array}{l}\text { Leaf mass per } \\
\text { area }\left(\mathrm{mg} \cdot \mathrm{cm}^{-2}\right)\end{array}$ & $\begin{array}{l}\text { Leaf stomata } \\
\text { length }(\mu \mathrm{m})\end{array}$ & $\begin{array}{l}\text { First bloom } \\
\text { (days after } \\
\text { planting) }\end{array}$ & $\begin{array}{l}\text { Blooming } \\
\text { period }(d)\end{array}$ & $\begin{array}{l}\text { Flower diam } \\
\quad(\mathrm{cm})\end{array}$ & $\begin{array}{c}\text { Flower } \\
\text { anthocyanin } \\
\text { content index }\end{array}$ \\
\hline $2 \mathrm{x}$ & 54 & 58 & 39.4 & 0.28 & 13.8 & 2.43 & 58 & 68 & 19.1 & 18.4 \\
\hline $3 x$ & 43 & 85 & 38.5 & 0.31 & 12.6 & $\mathrm{n} / \mathrm{a}^{\mathrm{z}}$ & 62 & 87 & 17.2 & 12.4 \\
\hline $\begin{array}{l}\text { Treatment }^{y} \\
3 \mathrm{x} \text { vs. } 2 \mathrm{x}\end{array}$ & $* * *$ & $* * *$ & NS & NS & NS & $\mathrm{n} / \mathrm{a}$ & NS & $* * *$ & $* * *$ & $* *$ \\
\hline
\end{tabular}

${ }_{\mathrm{z}}$ Leaf stomata length was not determined for triploid plants.

y***significant at $P \leq 0.001, * *$ significant at $P \leq 0.01, \mathrm{NS}=$ not significant, $\mathrm{n} / \mathrm{a}=$ not applied. 


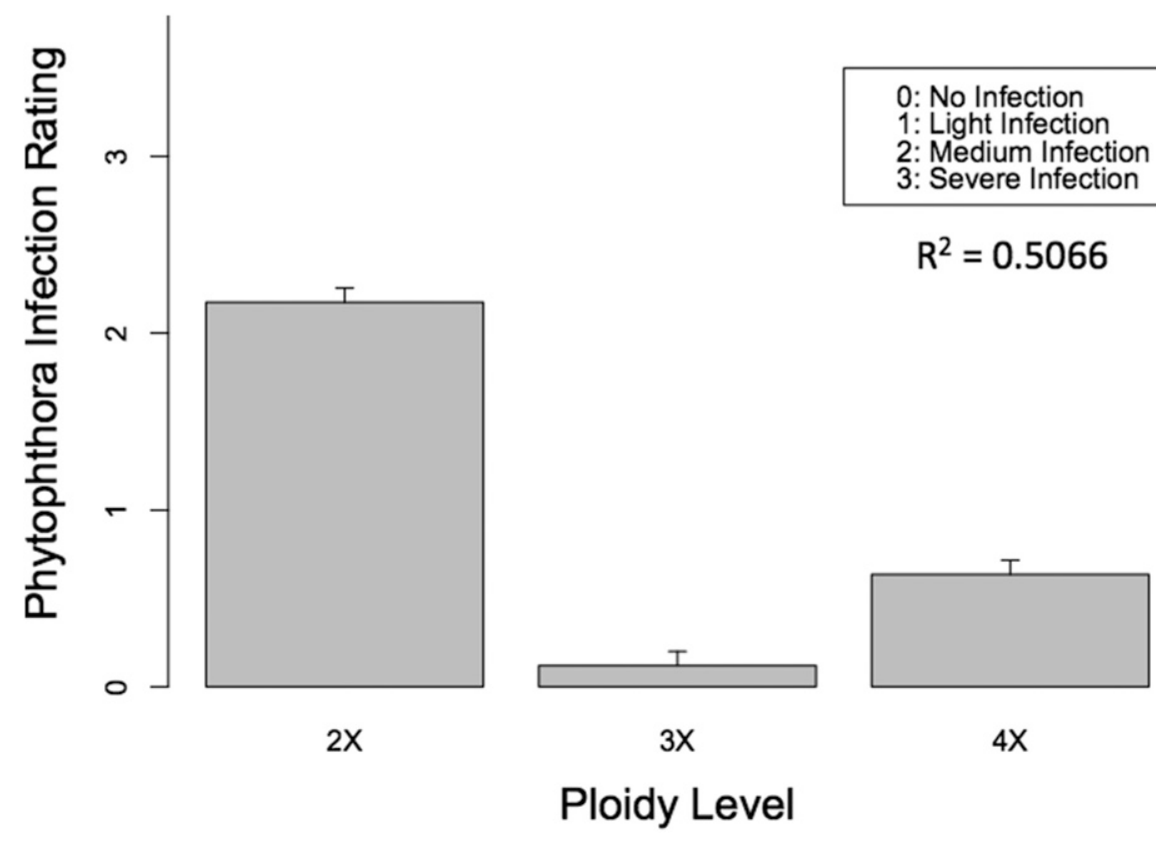

Fig. 3. Aerial phytophthora infection index on diploid, triploid, and tetraploid of Hibiscus moscheutos 'Luna Red'. Different letters indicate significant differences according to Tukey's honestly significant difference test at $P \leq 0.05$.

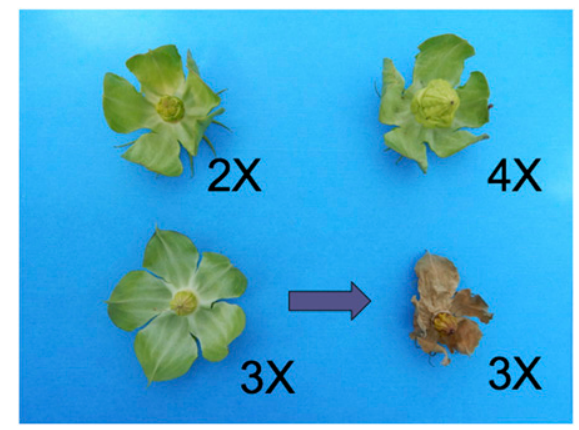

Fig. 4. Fruit development of diploid, triploid, and tetraploid Hibiscus moscheutos 'Luna Red'. Both fruit on diploid and tetraploid plants developed normally. Triploid plants displayed fruit setting for the first few days, but the fruit eventually aborted.

meanwhile, triploids were the shortest among the three groups, with large leaves (Table 3). Leaves of tetraploids possessed a leathery texture, whereas leaves of diploids and triploids had a papery texture (Fig. 2).

Tetraploids started blooming slightly earlier $(P=0.394)$ than diploids, and triploids started slightly later $(P=0.593)$ than diploids, but the differences were not statistically significant. Triploids, however, exhibited a longer blooming period than diploids $(P<0.001)$. This corresponded with the hypothesis of having an extended blooming period for polyploids with reduced fertility. Leaf stomata length was only measured in diploid and tetraploid plants, and there was no significant difference between levels of ploidy (Table 3 ). Similar results were found by Contreras et al. (2009) on Hibiscus acetosella 'Panama were on display, with no pollen shedding. Triploid flowers produced abundant pollen, and in $1 \%$ acetocarmine solution, pollen grains stained a dark red color. However, when pollen was cultured in BK agar media, no pollen tube germination was observed on pollen from triploid plants whereas pollen tubes of diploids started elongating after $4 \mathrm{~h}$.

Both diploid and tetraploid plants produced normal fruits from successful pollination until the fruit matured and dehisced. In an open pollination environment, fruits formed on triploids and were set for 1-3 d until selfabortion occurred (Fig. 4). Throughout the whole blooming and seed production season, no fruit were found growing or maturing on triploid plants at any stage of the blooming season.

\section{Discussion}

In the seedling experiment, both colchicine and oryzalin had an inhibitory effect during plant development (Hancock, 1997; Tomlin, 1997); however, a higher polyploidization efficiency was obtained by soaking seedlings in oryzalin. A low concentration of oryzalin exhibited a higher efficiency than colchicine at any tested level in inducing tetraploidy, due firstly to its lower toxicity compared with colchicine (Blakeslee and Avery, 1937) and secondly to its stability, as fewer plants reverted from tetraploid or triploid in the next generation. Though instability is typical among induced autotetraploids (Ranney, 2006; Soltis et al., 2014), continuous vegetative propagation maintained the different levels of ploidy. It is apparent from this study that colchicine-derived tetraploids were often unstable cytochimeras lacking tetraploids cells in the L2 layer and thus bred as diploids.

Tetraploid and triploid plants displayed a decrease in height, as expected (Contreras et al., 2009), and infertile triploid plants maintained a longer blooming time without interruption from seed production. Although leaves of tetraploid plants were thicker, greener, and more leathery than diploid plants, the test on LMA showed no difference between leaves of tetraploid and diploid plants. A similar result has been found in a previous study on japanese privet (Fetouh et al., 2016). LMA is known to be an important morphological trait, as well as an indicator of physiological traits, such as potential growth rate (De la Riva et al., 2016). Thus, induced tetraploids and triploids did not show a difference in vegetative growth rate, and also retained the same leaf tissue density, but a greater leaf thickness in tetraploid plants was observed because of its more ruffled leaf texture. A higher degree of resistance to aerial phytophthora was observed in tetraploid and triploid plants, whereas the triploid plants had almost no infection with clean leaves until the end of the growing season.

Induced tetraploid and triploid plants displayed no improvement in flower size but 
showed a decrease. Flowers of triploids also showed a decrease in the redness of flower petals from diploid plants. Incorporating more distinct parents should encourage higher degree of hybrid vigor in promoting the expression of "enlargement effects" (Acquaah, 2007) on phenotypic traits. Reduced pollen production was observed in tetraploid plants, whereas both pollen and seed production were observed in triploid plants. Triploid plants exhibited an extension in blooming period as a result of disabled seed production.

This study generated a seedling-soaking protocol manipulating $H$. moscheutos ploidy levels and found that, on an induced inbred triploid, there was an increase in tolerance to disease damage and a decrease in seed production along with an extended period for blooming. More than merely creating new selections for cultivar development, polyploidy induction in $H$. moscheutos opens the gate for future breeding endeavors. The next step for this study is to implement this protocol on the other available diploid H. moscheutos. With the combination of "Gigas effect" and heterosis, we are anticipating both a decrease in fertility and an improvement of ornamental traits.

\section{Literature Cited}

Acquaah, G. 2007. Principles of plant genetics and breeding. Blackwell Pub., Malden, MA.

Bartels, P.G. and J.L. Hilton. 1973. Comparison of trifluralin, oryzalin, pronamide, propham, and colchicine treatments on microtubules. Pestic. Biochem. Physiol. 3:462-472.

Blakeslee, A.F. and A.G. Avery. 1937. Methods of inducing doubling of chromosomes in plants by treatment with colchicine. J. Hered. 28:393-411.

Brewbaker, J.L. and B.H. Kwack. 1963. The essential role of calcium ion in pollen germination and pollen tube growth. Amer. J. Bot. 50:859-865.
Caporali, S., S.B.M. Hammami, I. Moreno-Alias, H.F. Rapoport, B. Chiancone, M.A. Germana, and A. Rosati. 2014. Effects of tetraploidy on olive floral and fruit biology. Sci. Hort. 179:198-203.

Contreras, R.N. and J.M. Ruter. 2009. An oryzalin induced polyploid from a hybrid of Hibiscus acetosella $x$ H. radiatus (Malvaceae) exhibits reduced fertility and altered morphology. HortScience 44:1177.

Contreras, R.N., J.M. Ruter, and W.W. Hanna. 2009. An oryzalin-induced autoallooctoploid of Hibiscus acetosella 'Panama Red'. J. Amer. Soc. Hort. Sci. 134:553-559.

De la Riva, E.G., M. Olmo, H. Poorter, J.L. Ubera, and R. Villar. 2016. Leaf mass per area (LMA) and its relationship with leaf structure and anatomy in 34 mediterranean woody species along a water availability gradient. PLoS One 11:e0148788.

Dixit, V. and B.R. Chaudhary. 2014. Colchicineinduced tetraploidy in garlic (Allium sativum L.) and its effect on allicin concentration. J. Hort. Sci. Biotechnol. 89:585-591.

Fetouh, M.I., A. Kareem, G.W. Knox, S.B. Wilson, and Z. Deng. 2016. Induction, identification, and characterization of tetraploids in Japanese privet (Ligustrum japonicum). HortScience 51:1371-1377.

Fiala, J.L. 1988. Use of colchicine in inducing polyploids, p. 187-188, Lilacs: The genus Syringa. Timber Press, Portland, OR.

Flora of North America Editorial Committee. 1993+. Flora of North America, Vol. 6. Oxford University Press, New York, NY.

Ghani, M.A., Q. Sun, J.X. Li, L.W. Cao, L.L. Rao, X.X. Zou, and L.P. Chen. 2014. Phenotypic and genetic variation occurred during wide hybridisation and allopolyploidisation between Brassica rapa and Brassica nigra. Sci. Hort. 176:22-31.

Hancock, J.F. 1997. The colchicine story. HortScience 32:1011-1012.

Kehr, A.E. 1996. Breeding for a purpose. Amer. Rhododendron Soc. Bul. 20:131-141.

Lambers, H., F.S.I. Chapin, and T.L. Pons. 1998. Growth and allocation, p. 308, Plant Physiological Ecology. Springer, Berlin, Germany.
Lehrer, J., M. Brand, and J. Lubell. 2007. Induction of tetraploidy in Japanese barberry (Berberis thunbergii DC.) seedlings through exposure to colchicine and oryzalin. HortScience 42:901.

Leue, E. 2005. Hibiscus moscheutos 'Bahlibred'. Ball Horticultural Company, West Chicago, IL.

Levin, D.A. 1983. Polyploidy and novelty in flowering plants. Amer. Nat. 122:1-25.

Olsen, R.T., T.G. Ranney, and D.J. Werner. 2006. Fertility and inheritance of variegated and purple foliage across a polyploid series in Hypericum androsaemum L. J. Amer. Soc. Hort. Sci. 131:725-730.

R Development Core Team. 2015. R: A language and environment for statistical computing, Version 3.2.2. R Foundation for Statistical Computing, Vienna, Austria.

Ranney, T.G. 2006. Polyploidy: From evolution to new plant development. Combined Proc. Intl. Plant Propagators Soc. 56:137-142.

Rubuluza, T., R.V. Nikolova, M.T. Smith, and K. Hannweg. 2007. In vitro induction of tetraploids in Colophospermum mopane by colchicine. S. Afr. J. Bot. 73:259-261.

Shimamura, R., N. Kachi, H. Kudoh, and D.F. Whigham. 2005. Visitation of a specialist pollen feeder Althaeus hibisci olivier (Coleoptera: Bruchidae) to flowers of Hibiscus moscheutos L. (Malvaceae). J. Torrey Bot. Soc. 132:197-203.

Soltis, D.E., C.J. Visger, and P.S. Soltis. 2014. The polyploidy revolution then... and now: Stebbins revisited. Amer. J. Bot. 101:10571078.

Spira, T.P. 1989. Reproductive biology of Hibiscus moscheutos (Malvaceae), p. 247-256. In: J.H. Bock and Y.B. Linhart (eds.), The evolutionary ecology of plants. Westview Press, Boulder, $\mathrm{CO}$.

Tomlin, C.D.S. 1997. The pesticide manual World Compendium. British Crop Protection Council, Surrey, England.

Trojak-Goluch, A. and U. Skomra. 2013. Artificially induced polyploidization in Humulus lupulus $\mathrm{L}$. and its effect on morphological and chemical traits. Breed. Sci. 63:393-399.

Winters, H.F. 1970. Our hardy Hibiscus species as ornamentals. Econ. Bot. 24:155-164. 